\title{
Eficiência do tratamento de sementes com o fungicida triadimenol na intensidade da ferrugem da folha do trigo
}

\author{
Erlei Melo Reis, Mateus Zanatta \& Fernando Brustolin
}

Universidade de Passo Fundo. Faculdade de Agronomia e Medicina Veterinária.

Autor para correspondência: Erlei Melo Reis (erleireis@tpo.com.br )

Data de chegada: 28/02/2011. Aceito para publicação em: 03/06/2011.

\section{RESUMO}

Reis, E. M.; Zanatta, T. Eficiência do tratamento de sementes com o fungicida triadimenol na intensidade da ferrugem da folha do trigo.Summa Phytopathologica, v.37, n.3, p.145-148, 2011.

A ferrugem da folha é uma das principais doenças do trigo. Os prejuízos causados variam em função da área cultivada com cultivar suscetível, das raças fisiológicas do patógeno e das condições climáticas. Em cultivares suscetíveis a melhor opção de controle disponível tem sido através do uso de fungicidas aplicados via tratamento de sementes. O objetivo deste trabalho foi verificar a eficiência desta tecnologia após 29 anos de uso no Brasil. O experimento foi conduzido no campo com dois cultivares de trigo, Pampeano e Ônix, no ano agrícola de 2009 , com infecção natural da ferrugem. No tratamento de sementes utilizou-se o fungicida triadimenol (15\% SC) em três doses da formulação comercial $(135,270,540 \mathrm{~mL} / 100 \mathrm{Kg}$ de sementes). A infecção foi natural e avaliou-se semanalmente a incidência foliar da ferrugem. Os dados foram submetidos à análise da variância, de regressão e calculada a área abaixo da curva de progresso da incidência da doença. Verificou-se que não houve diferença significativa entre doses do fungicida e a intensidade da doença no tratamento testemunha, no entanto, houve diferença quanto à intensidade da ferrugem entre os dois cultivares.

Palavras-chave adicionais: Controle químico, Triticum aestivum, Puccinia triticina.

\section{ABSTRACT}

Reis, E. M.; Zanatta, T. Efficiency of seed treatment with triadimenol fungicide on the intensity of wheat leaf rust. Summa Phytopathologica, v.37, n.3, p.145-148, 2011

Leaf rust is one of the main diseases affecting wheat. The damages vary according to the area cultivated with susceptible cultivar, the pathogen physiological races and the climate conditions. The best control strategy for susceptible cultivars has been the use of fungicide applied to seeds as treatment. The aim of this study was to verify the efficiency of this technology after 29 years of use in Brazil. The field experiment was conducted with two wheat cultivars, Pampeano and Ônix, with natural rust infection in 2009 growing season. For seed treatment, the fungicide triadimenol $(15 \% \mathrm{SC})$ was used at three levels of the commercial formulation $(135,270,540 \mathrm{~mL} / 100 \mathrm{Kg}$ seeds). Rust infection was natural and the leaf rust incidence was weekly assessed. Data were subjected to analysis of variance and regression analysis, and the area under the disease incidence progress curve was calculated. There were no significant differences among fungicide levels and disease intensity in the control treatment; however, there was difference for rust intensity between cultivars.

Keywords: Chemical control, triadimenol Triticum aestivum, Puccinia triticina

O trigo (Triticum aestivum L.) é uma importante cultura de inverno no sul do Brasil. A produção anual brasileira oscila entre 5 e 6 milhões de toneladas, tendo um consumo em torno de 10 milhões de toneladas. A região sul do Brasil é responsável por cerca de $90 \%$ da produção de trigo (8).

A cultura do trigo é atacada por várias doenças causadas, principalmente, por fungo. Sua ocorrência e intensidade são favorecidas pelo clima onde predominam temperaturas altas e precipitações pluviais freqüentes. Essas doenças podem ser responsáveis por danos elevados no rendimento e qualidade dos grãos. Dentre as doenças, merece destaque a ferrugem da folha causada pelo fungo Puccinia triticina Erickson, por ser a mais comum e com danos que podem chegar a $63 \%$ $(7,8)$ Os danos em rendimento dependem do estádio fenológico da planta em que a doença ocorre e, principalmente, da severidade, a qual é função da suscetibilidade da cultivar, da virulência da raça fisiológica e das condições de ambiente (10).
Dentre as medidas de controle das doenças de trigo, o uso de cultivares resistente é a preferencial (11). Entretanto, não se dispõem de cultivares resistente a todas as enfermidades. Outras medidas como o tratamento de sementes, a rotação de culturas e a eliminação de plantas voluntárias e de hospedeiros secundários, auxiliam na redução do inóculo dos patógenos. Além dessas táticas, dispõem-se, do controle químico recomendado para cultivares suscetíveis (10).

$\mathrm{O}$ triadimenol, fungicida inibidor da desmetilação (IDM), tem sido largamente usado via tratamento de semente visando ao controle do oídio [Blumeria graminis (DC) Speer.] em cevada e em trigo (10). Os fungicidas são usados tradicionalmente em aplicações nos órgãos aéreos das plantas. No caso de fungicidas aplicados via tratamento de sementes, são absorvidos pelo sistema radicular das plântulas e translocado via xilema para os órgãos aéreos conferindo proteção ao oídio e ferrugem da folha. Devido a esta propriedade, o triadimenol tem sido usado no tratamento de sementes de cevada e de trigo visando 


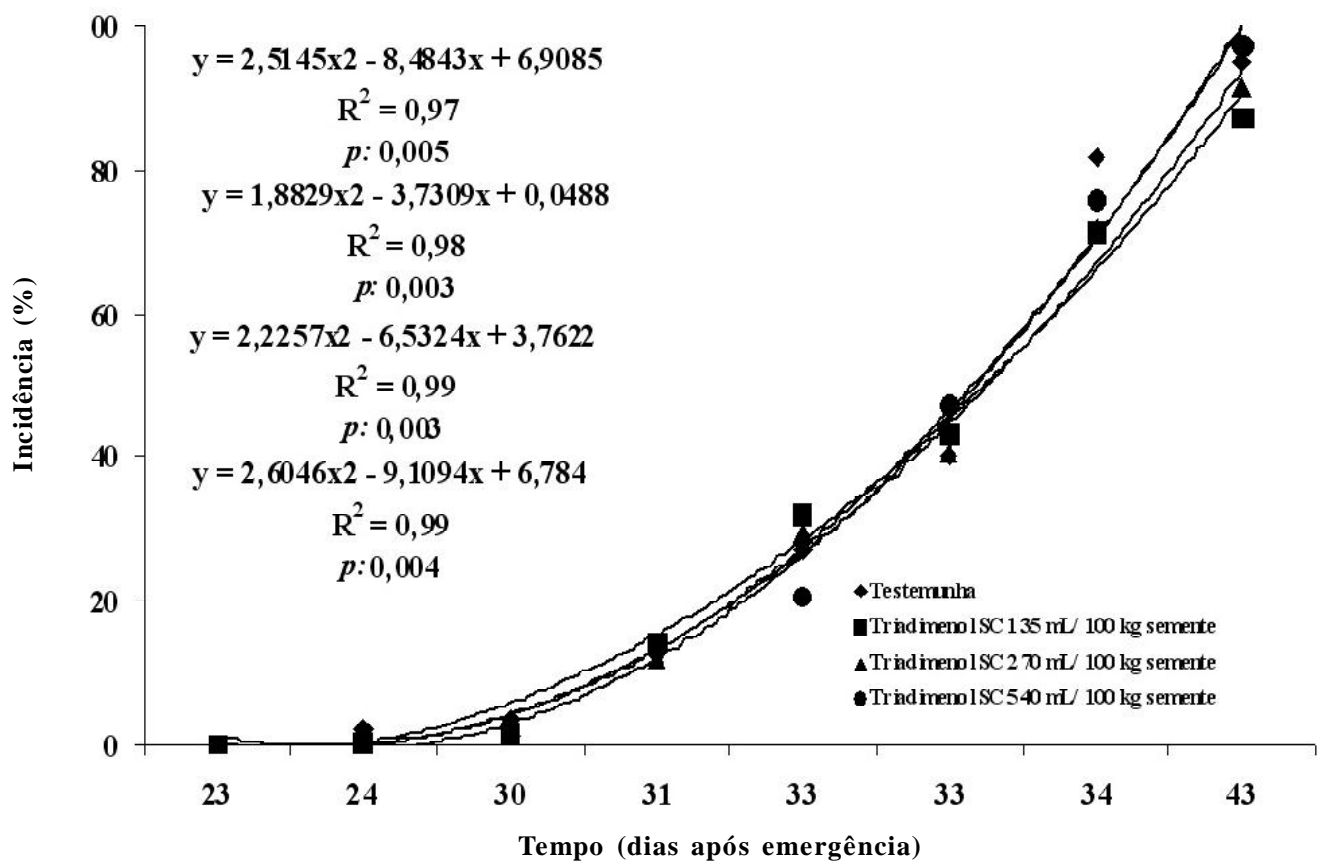

Figura 1. Curvas de progresso da incidência foliar da ferrugem da folha do trigo no cultivar Ônix em função do tratamento de sementes com diferentes doses da formulação comercial do triadimenol. Safra 2008, FAMV/UPF, Passo Fundo, RS.

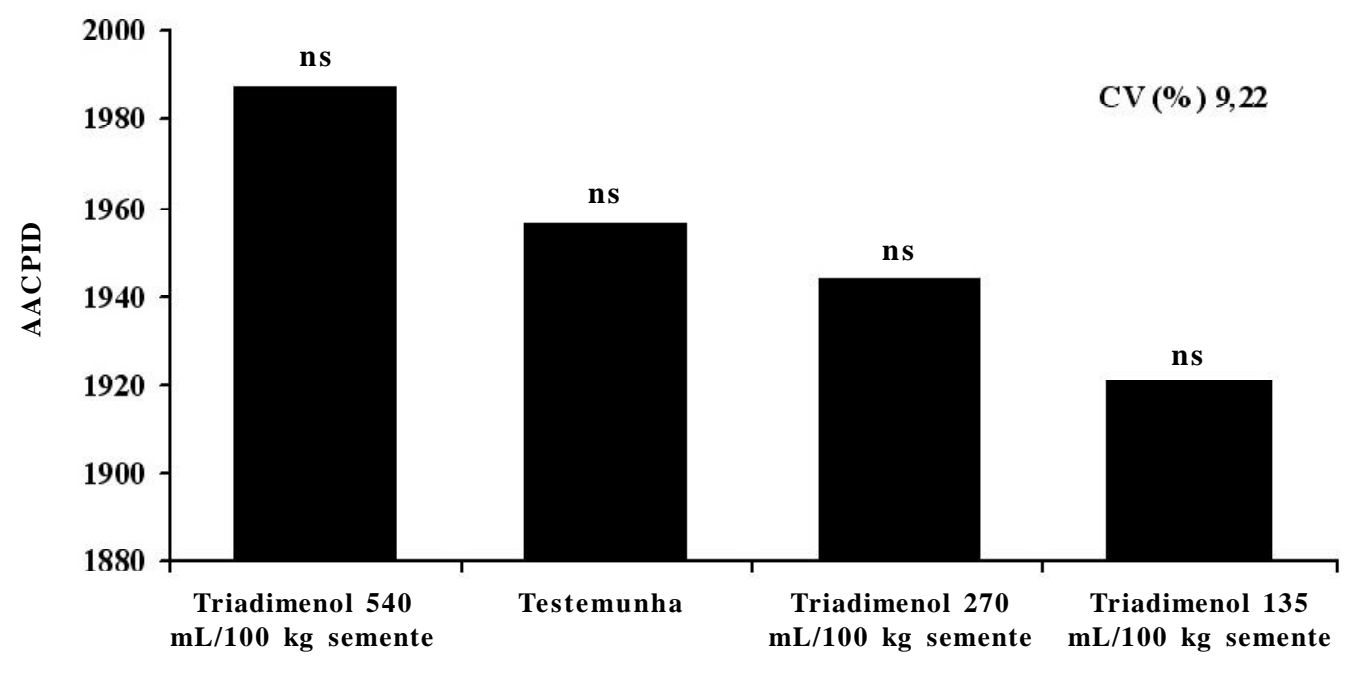

Tratamentos

Figura 2. Efeito de doses da formulação comercial do fungicida triadimenol aplicado via tratamento de sementes na intensidade da ferrugem representada pela área abaixo da curva de progresso da incidência da ferrugem da folha (AACPID) no trigo cultivar Ônix. Safra 2008, FAMV/UPF, Passo Fundo, RS (ns - não significativo).

principalmente ao controle do oídio causado por B. graminis desde $1980(9,10)$. Quando a semente tratada é semeada, o produto é diluido na água do solo e absorvido lentamente pelas raízes conferindo proteção nos órgãos áereos por até 60 dias (8). Casa (informação pessoal, 2010) verificou o potencial de controle da ferrugem da folha do trigo pelo tratamento de sementes, com o triadimenol, tendo obtido em experimento de campo proteção de até 40 dias.

Este trabalho teve como objetivo revisar o desempenho da aplicação do fungicida triadimenol via tratamento de sementes, no controle da ferrugem da folha, após 29 anos de uso na cultura do trigo no Brasil.
O experimento foi conduzido no Campo Experimental da Faculdade de Agronomia e Medicina Veterinária da Universidade de Passo Fundo com delineamento experimental de blocos casualizados, com quatro repetições. O ensaio foi implantado no período mais recomendado para a cultura com parcelas de $1,19 \mathrm{~m}$ de largura por 5,0 m de comprimento totalizando $5,95 \mathrm{~m}^{2}$. Foi utilizada uma adubação de base com $250 \mathrm{~kg} / \mathrm{ha}$ da fórmula comercial 5-20-20 $\left(\mathrm{N}-\mathrm{P}_{2} \mathrm{O}_{5}-\mathrm{K}_{2} \mathrm{O}\right)$ e $130 \mathrm{~kg} / \mathrm{ha}$ de nitrogênio, na forma de uréia $(45 \% \mathrm{~N})$, em cobertura, no estádio fenológico do afilhamento. Utilizaram-se os cultivares de trigo Ônix e Pampeano, suscetíveis à ferrugem da folha, semeados 


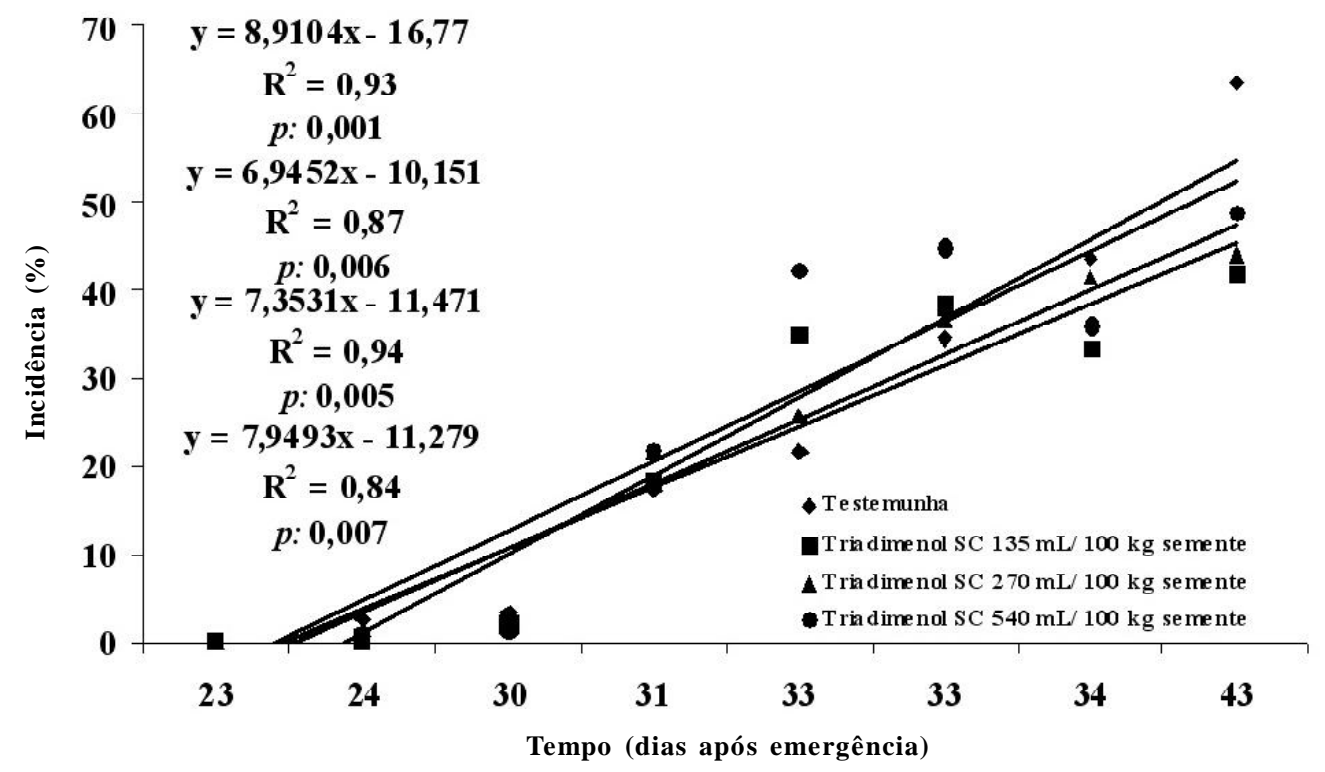

Figura 3. Linhas de progresso da incidência foliar da ferrugem da folha do trigo no cultivar Pampeano em função do tratamento de sementes com diferentes doses da formulação comercial do triadimenol. Safra 2008, FAMV/UPF, Passo Fundo, RS.

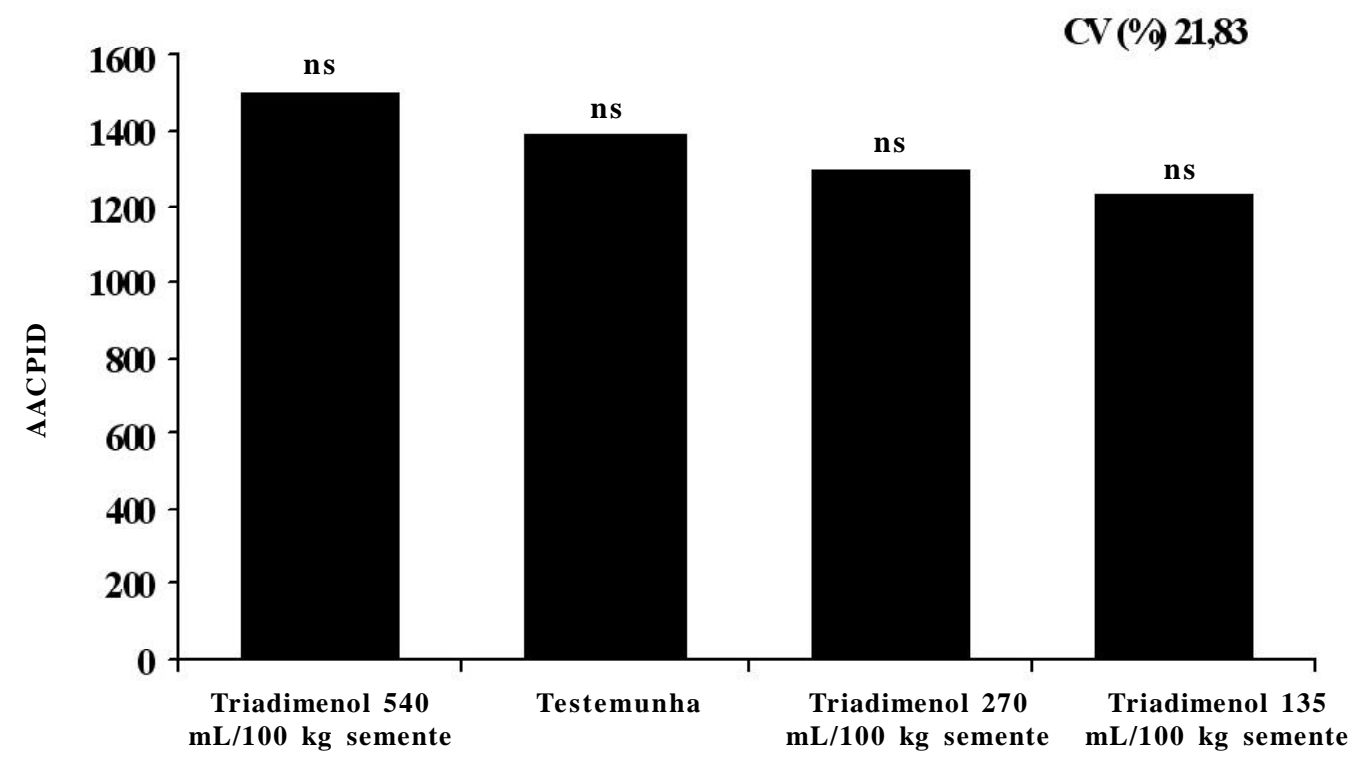

Tratamentos

Figura 4. Efeito de doses da formulação comercial do fungicida triadimenol aplicado via tratamento de sementes na intensidade ferrugem, representada pela área abaixo da curva de progresso da incidência foliar da ferrugem da folha (AACPID) no trigo cultivar Pampeano. Safra 2008, FAMV/UPF, Passo Fundo, RS (ns - não significativo).

mecanicamente no espaçamento de $0,17 \mathrm{~m}$ entre linhas, e a semeadora regulada com 60 sementes por metro e densidade de 400 sementes $/ \mathrm{m}^{2}$.

O fungicida utilizado para o tratamento das sementes foi o triadimenol (Baytan ${ }^{\circledR} 15 \% \mathrm{SC}$ ) nas doses de 0, 135, 270, $540 \mathrm{~mL} / 100$ $\mathrm{Kg}$ de sementes da formulação comercial. O preparo da calda para o tratamento das sementes foi realizado em um becker com capacidade de $100 \mathrm{~mL}$ onde se adicionou $1 \%$ de água. Após a calda foi vertida em um saco plástico contendo $0,8 \mathrm{~kg}$ de sementes e em seguida agitado por cinco minutos até proporcionar a melhor distribuição e a máxima cobertura das sementes.

Para a quantificação da evolução da ferrugem, foram coletadas semanalmente 25 folhas, em média, por unidade experimental. As amostras foram levadas ao laboratório onde foram procedidas as avaliações da incidência (\%) foliar. Considerou-se doente a folha na 


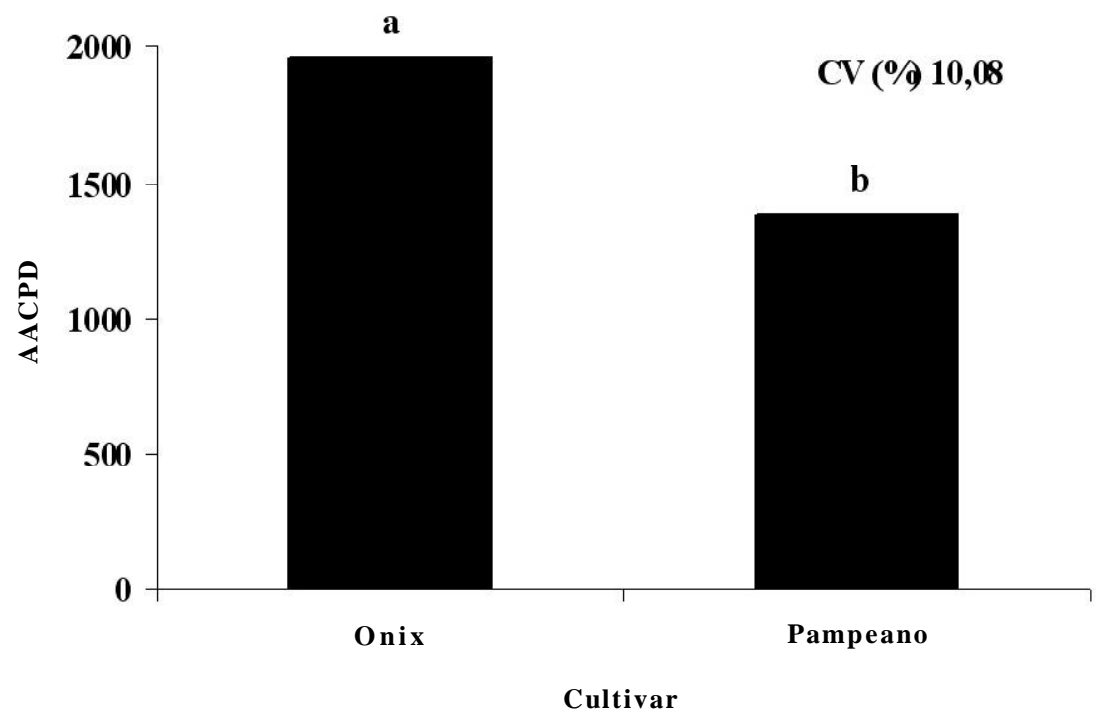

Figura 5. Áreas abaixo da curva de progresso da incidência foliar (AACPID) da ferrugem da folha do trigo, no tratamento testemunha, nos cultivares Ônix e Pampeano. Safra 2008, FAMV/UPF, Passo Fundo, RS. a e b = diferença significativa.

qual se visualizou, a olho nu, pelo menos uma pústula esporulante. Uma mostra de folhas com sintomas/sinais da ferrugem, de cada cultivar, foi encaminhada a OR-Melhoramento e Sementes, Passo Fundo, RS (www.orsementes.com.br) para a identificação das raças fisiológicas de $P$. triticina.

Foram feitas oito avaliações durante o ciclo do trigo até a epidemia atingir $100 \%$ de incidência foliar.

Observou-se o delineamento fatorial envolvendo os fatores cultivar (2) e doses do fungicida (4). Os dados foram submetidos à análise da variância, de regressão e calculada a área abaixo da curva de progresso da incidência da doença (AACPID) conforme Campbell \& Madden (4) cujas médias foram comparadas pelo teste de Tukey $(p=0,05)$.

No cultivar Ônix a ferrugem da folha foi precocemente detectada, aos 23 dias após a emergência, e no Pampeano aos 25 dias (Figuras 1 e 3). Estes dados mostram quão precoce no ciclo do trigo a doença ocorre em cultivares suscetíveis. As curvas de progresso da incidência foliar da ferrugem foram semelhantes, independentemente de doses (Figuras 1, 2, 3 e 4). A análise de variância dos dados da AACPID mostrou não haver efeito das doses do fungicida triadimenol no controle da ferrugem, para ambos os cultivares.

No cultivar Ônix foi identificada a raça de $P$. triticna MDT-MR e no Pampeano as raças MDT-MR 40002S e TDT-MR, de acordo com a nomenclatura americana (6). Estas raças apresentam redução da sensibilidade aos fungicidas IDM (inibidores da desmetilação) como comprovada por Arduim et al. $(1,2)$ e Arduim (3). Portanto, o fato de não haver efeito de doses do fungicida, comparado com a testemunha, pode ser atribuído a redução da sensibilidade de raças de $P$. triticina aos fungicidas IDMs, entre eles o triadimenol.

A alteração da sensibilidade de $P$. triticina ao fungicida triadimenol torna o tratamento de sementes ineficiente independentemente da reação do cultivar e das doses do fungicida. No entanto, houve diferença significativa (Teste F) quanto a reação dos cultivares sendo o Ônix mais suscetével do que o Pampeano. A AACPID no Ônix foi de 1.956 e do Pampeano de 1.382 unidades (Figura 5).

\section{REFERÊNCIAS BIBLIOGRÁFICA}

1. Arduim, G. da S.; Reis, E. M.; Barcellos, A. L. Sensibilidade de Puccinia triticina quando tratadas preventivamente com diferentes fungicidas in vivo. Fitopatologia Brasileira, Brasília, v. 32, n. Suplemento, p. S194 2007a. (Resumo n. 423).

2. Arduim, G. da S.; Reis, E. M.; Barcellos, A.L. Sensibilidade de raças de Puccinia triticina quando tratadas curativamente com diferentes fungicidas in vivo. Fitopatologia Brasileira, Brasília, v. 32, n. Suplemento, p. S194, 2007b. (Resumo n. 424).

3. Arduim, G. da S. Sensibilidade de raças de Puccinia triticina a fungicidas. 2009, UPF. Tese (Doutorado em Agronomia) - Universidade de Passo Fundo, 2009

4. Campbell, C.L.; Madden, L.V. Introduction to plant disease epidemiology. New York: Wiley, 1990. 532 p.

5. EMBRAPA. Trigo. *Disponível em*: $<$ http:// www.cnpso.embrapa.br>. Acesso em: 06 nov. 2008.

6. Long, D.L.; Kolmer, J.A. A North American system of nomenclature for Puccinia triticina. Phytopathology, St. Paul, v.79, n. 5, p.525-529, 1989.

7 . Reis, E. M. Doenças do trigo - V: Ferrugens. São Paulo: Bayer do Brasil, 1991. 20 p.

8. Reis, E. M.; Forcelini, C. A.; Reis, A. C. Manual de fungicidas: guia para o controle químico de doenças de plantas. Florianópolis: Insular, 2007. $176 \mathrm{p}$.

9. Reis, E.M., Casa, R.T.; Hoffmann, L.L. Efeito de oídio, causado por Erysiphe graminis f. sp. tritici sobre o rendimento de grãos de trigo. Fitopatologia Brasileira, Brasília, v.22, n.1, p. 492495, 1997.

10. Reunião Da Comissão Brasileira De Pesquisa De Trigo E Triticale, 2., 2008, Passo Fundo. Informações técnicas para a safra 2009: trigo e triticale. Passo Fundo: Comissão Brasileira de Pesquisa de Trigo e Triticale. Embrapa Trigo. Embrapa transferência de Tecnologia, 2008. 172 p.

11. Roelfs, A.P.; Singh, R.P.; Saari, E.E. Las royas del trigo: conceptos y métodos para el manejo de esas enfermedades. México: CIMMYT, 199, $81 \mathrm{p}$. 